\title{
Validation of NOAA-Interactive Multisensor Snow and Ice Mapping System (IMS) by Comparison with Ground-Based Measurements over Continental United States
}

\section{Christine Chen ${ }^{1,2}$, Tarendra Lakhankar ${ }^{1, *}$, Peter Romanov ${ }^{1}$, Sean Helfrich ${ }^{3}$, Al Powell ${ }^{4}$ and Reza Khanbilvardi ${ }^{1}$}

1 NOAA-Cooperative Remote Sensing and Technology Center (NOAA-CREST), New York, NY 10031, USA; E-Mails: cchen18@ ccny.cuny.edu (C.C.); peter.romanov@noaa.gov (P.R.); khanbilvardi@ccny.cuny.edu (R.K.)

2 Byrd Polar Research Center, The Ohio State University, Columbus, OH 43210, USA

3 National Ice Center, NOAA, Washington, DC 20395, USA; E-Mail: Sean.Helfrich@ @oaa.gov

4 Center for Satellite Application and Research, NOAA, Washington, DC 20395, USA;

E-Mail: Al.Powell@ noaa.gov

* Author to whom correspondence should be addressed; E-Mail: tlakhankar@ccny.cuny.edu;

Tel.: +1-212-650-5815; Fax: +1-212-650-8097.

Received: 3 March 2012; in revised form: 17 April 2012 / Accepted: 17 April 2012 /

Published: 25 April 2012

\begin{abstract}
In this study, daily maps of snow cover distribution and sea ice extent produced by NOAA's interactive multisensor snow and ice mapping system (IMS) were validated using in situ snow depth data from observing stations obtained from NOAA's National Climatic Data Center (NCDC) for calendar years 2006 to 2010. IMS provides daily maps of snow and sea ice extent within the Northern Hemisphere using data from combination of geostationary and polar orbiting satellites in visible, infrared and microwave spectrums. Statistical correspondence between the IMS and in situ point measurements has been evaluated assuming that ground measurements are discrete and continuously distributed over a $4 \mathrm{~km}$ IMS snow cover maps. Advanced Very High Resolution Radiometer (AVHRR) land and snow classification data are supplemental datasets used in the further analysis of correspondence between the IMS product and in situ measurements. The comparison of IMS maps with in situ snow observations conducted over a period of four years has demonstrated a good correspondence of the data sets. The daily rate of agreement between the products mostly ranges between $80 \%$ and $90 \%$ during the Northern Hemisphere through the winter seasons when about a quarter to one third of the territory of
\end{abstract}


continental US is covered with snow. Further, better agreement was observed for stations recording higher snow depth. The uncertainties in validation of IMS snow product with stationed NCDC data were discussed.

Keywords: snow; IMS; NOAA; NCDC; AVHRR

\section{Introduction}

Snow cover plays a critical role in regional to global scale hydrological modeling [1,2]. Rain-on-snow with warm air temperatures accelerates rapid snow-melt, which is responsible for the majority of the spring floods. Remote sensing measurements in the visible and near infrared part of spectrum have shown great potential in providing information on the snow cover extent. Satellite sensors such as the Advanced Very High Resolution Radiometer (AVHRR) onboard NOAA satellites, Moderate Resolution Imaging Spectroradiometer (MODIS) onboard Earth Observing System (EOS) satellites and Imager instrument onboard Geostationary Operational Environmental Satellites (GOES) have been used for snow cover mapping [3-5].

Both interactive and automated techniques have been used to process satellite observations, identify snow cover in satellite imagery and generate maps of snow cover distribution. The automated techniques have a limitation in accurately differentiating clouds, fog with ice and snow compared to an interactive technique [5]. In addition, the bright surface features or boundaries between water bodies and land can increase erroneous snow detection. These errors are eliminated using interactive techniques where multiple images were used along with microwave data [6].

NOAA's IMS is an interactive system that is used to examine satellite images and other sources of data on snow cover and to generate maps of snow cover distribution (Figure 1). The IMS product became operational in 1997, and was first available in $24 \mathrm{~km}$ resolution [7]. Since its inception in 1997, it has been continuously upgraded. The improvements include additional input sources to the product and improved output resolution from $24 \mathrm{~km}$ to $4 \mathrm{~km}$. The visible and infrared spectral data from Polar and Geostationary Operational Environmental Satellites are used generate snow cover data. Since, the visible and infrared data suffer from persistent cloud cover and making observations difficult, microwave products from SSM/I (Special Sensor Microwave Imager) and AMSR-E (Advanced Microwave Scanning Radiometer for EOS) are being ingested in IMS product. The IMS system also includes the model output from SNOw Data Assimilation System (SNODAS) and station-mapped products.

The spatial resolution of visible, infrared, microwave and SNODAS product used in IMS System are varied from 1 to $40 \mathrm{~km}$. IMS analysts use these multiple sources with different spatial resolution within the interactive multisensor snow and ice mapping system to re-gridded to map snow and sea ice extent in $4 \mathrm{~km}$ spatial resolution. The analyst begins charting using the map from the previous day, then uses the satellite inputs accordingly [6]. The daily IMS maps replaced weekly maps of snow and sea ice extent drawn by hand since 1966. The IMS system allows for faster processing time to produce snow cover maps from satellite remote sensing data [8]. 
Figure 1. NOAA's interactive multisensor snow and ice mapping system (IMS) product shows ice and snow cover extent in the North Hemisphere in a Plate Carree projection.

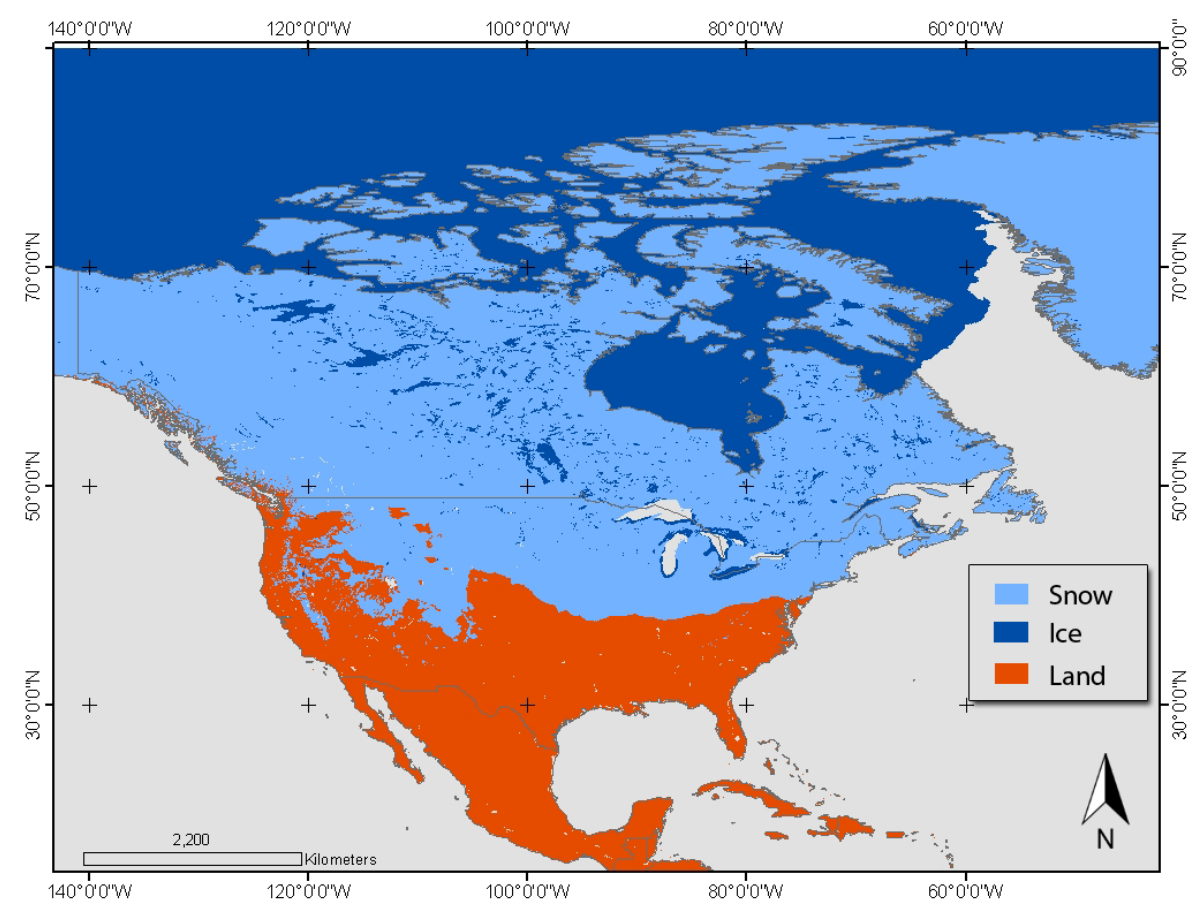

IMS snow cover product is being used in hydrological applications, numerical weather prediction models and in climate studies $[9,10]$. For the users it is important to know the accuracy of the product and its limitations. The accuracy of snow detection varies based on land cover characteristics. For example, in the dense forest, snow on the ground, may not be visible to the satellite sensors through dense canopy. The reflectance of land surface albedo that mixed with reflectance of fresh and aged snow, introduces additional error in snow detection. Therefore, snow products should be tested for different land cover and snow properties. This requires the comparison of the snow cover product with ground measurements. In the past, several studies have been conducted to evaluate the accuracy of IMS snow product $[6,11]$.

This study will explore North American snow coverage through the comparison of IMS snow maps with ground-truth data obtained from NOAA's National Climatic Data Center (NCDC). The daily snow coverage record of the North American region of the IMS product was compared to the daily NCDC snow depth archives of the United States using supplemental datasets including AVHRR land classification and snow classification data.

\section{Study Area and Data Sets}

The study area includes the United States and southern Canada within 30 to $60^{\circ} \mathrm{N}$ and 60 to $140^{\circ} \mathrm{W}$. In the study area, monthly mean snow cover extent increases from the early snow season in November, and reaches peak extent in January. Then snow depth keeps increasing steadily until March, without significant increase in snow cover extent [12]. Daily IMS snow maps over the course of the January 2006-February 2010 period were obtained from the IMS website (http://www.natice.noaa.gov/ims/). The in situ observations from station data is acquired from NCDC for the continental USA (Figure 2). The in situ data from NCDC archive consist of $24 \mathrm{~h}$ precipitation/snow and ice pellets. The study 
period allows for coverage over more than three complete snow seasons. The NCDC data were quality controlled by removing outlier stations that are not reporting the data.

Figure 2. The distribution of National Climatic Data Center (NCDC) meteorological observing stations within the continental USA.

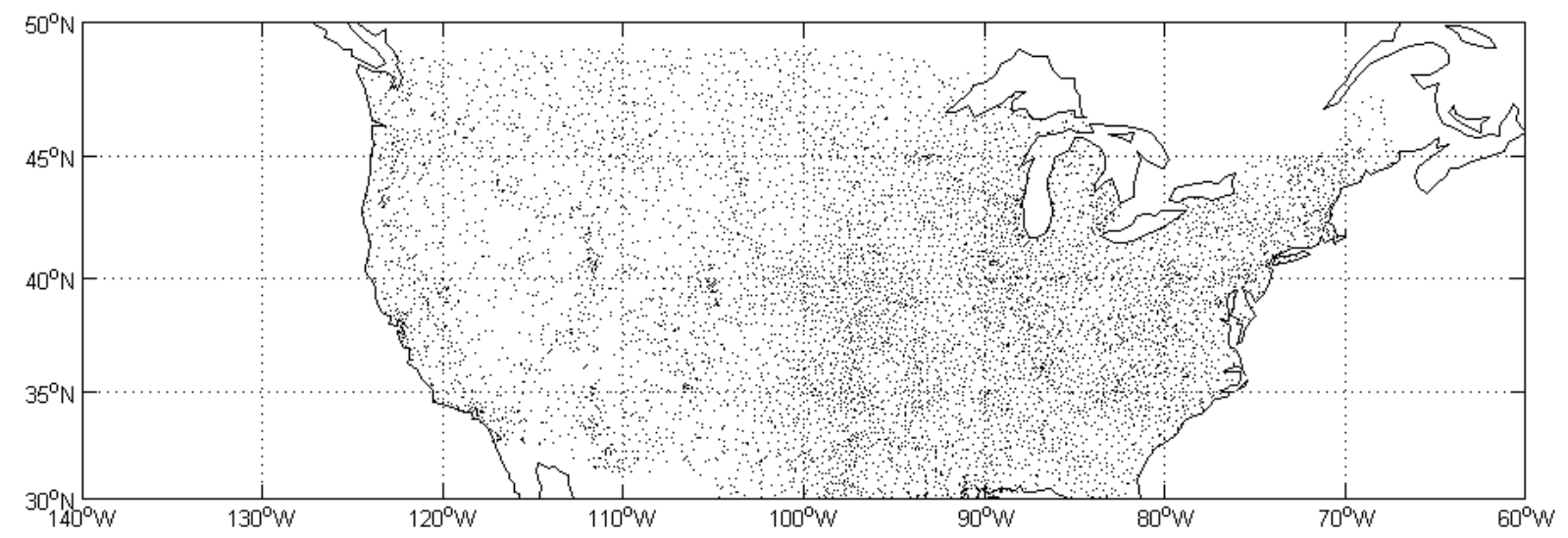

Figure 3. Flow chart shows station-wide validation process of NOAA-IMS Snow Cover Maps by comparison with ground-based measurements.

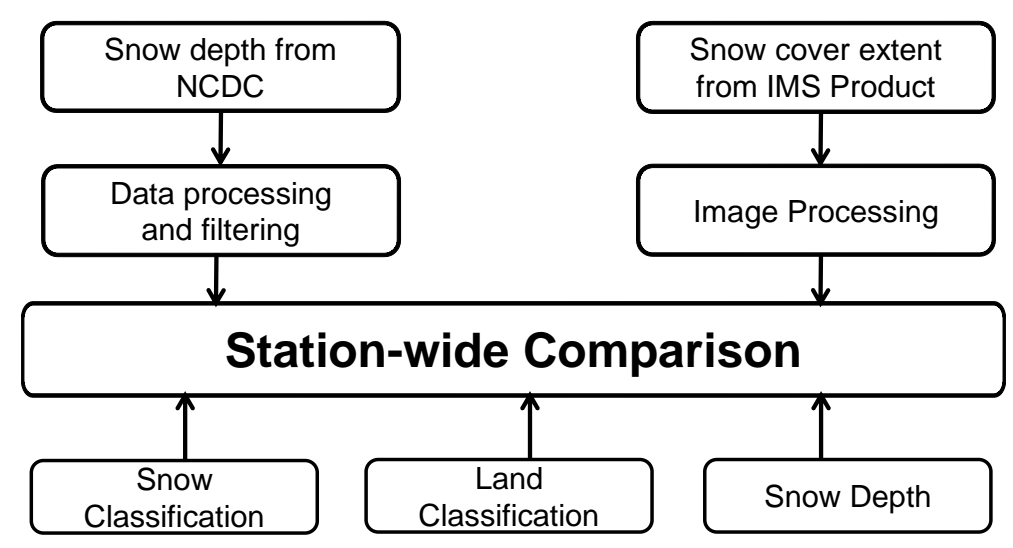

\section{Methodology}

Validation of the snow extent from the IMS product was performed through NCDC in situ station-wide comparison of snow depth archives. Results are further investigated through a time-series analysis involving land classification, snow classification, and breakdowns in snow depth from NCDC stations are shown in Figure 3. Out of 10,129 NCDC observing stations, 8,659 stations (or 85.5\%) were selected within the study area based on the criteria that these stations recorded at least one snow depth measurement during the January 2006-February 2010 study period. Care was taken to ensure that these stations did not coincide with a sea or sea ice IMS pixel. Supplemental latitude and longitude grid cells in degree decimal format were extracted from the IMS datasets. The daily polar stereographic Northern Hemispherical IMS images were cropped to process the images more quickly. The latitude and longitude coordinates for each of the observing stations were used to determine the closest pixel in the IMS image.

IMS pixel values (snow or land or ice) were compared to the snow depth values of the NCDC observing stations. For a given NCDC station location, which coincides within IMS pixel, a 'match' 
was tagged if the IMS pixel value was 'snow' and a snow depth value from in situ data shows 'trace' or larger value. Similarly, if the IMS pixel was classified as 'land' and a snow depth value from in situ data ' 0 ' was recorded, is considered as 'match'. A 'mismatch' occurs if either the IMS pixel was 'snow' and a snow depth from in situ data shows '0' or if the IMS pixel was classified as 'land' and a snow depth value from in situ data shows 'trace' or larger. If the observing station value was missing for that day, it was tagged as 'missing'. Comparisons to the IMS were not performed for those stations tagged as a 'missing'. A daily agreement between the IMS snow pixel and NCDC data was calculated as the number of matching pixels divided by the sum of matching pixels and mismatching pixels multiplied by a hundred.

$$
\text { Agreement }=\frac{\text { matching pixels }}{\text { matching pixels }+ \text { mismatching pixels }} * 100
$$

Figure 4. Land cover classification data derived from Advanced Very High Resolution Radiometer (AVHRR) with $1 \mathrm{~km}$ spatial resolution covers study area (continental USA).

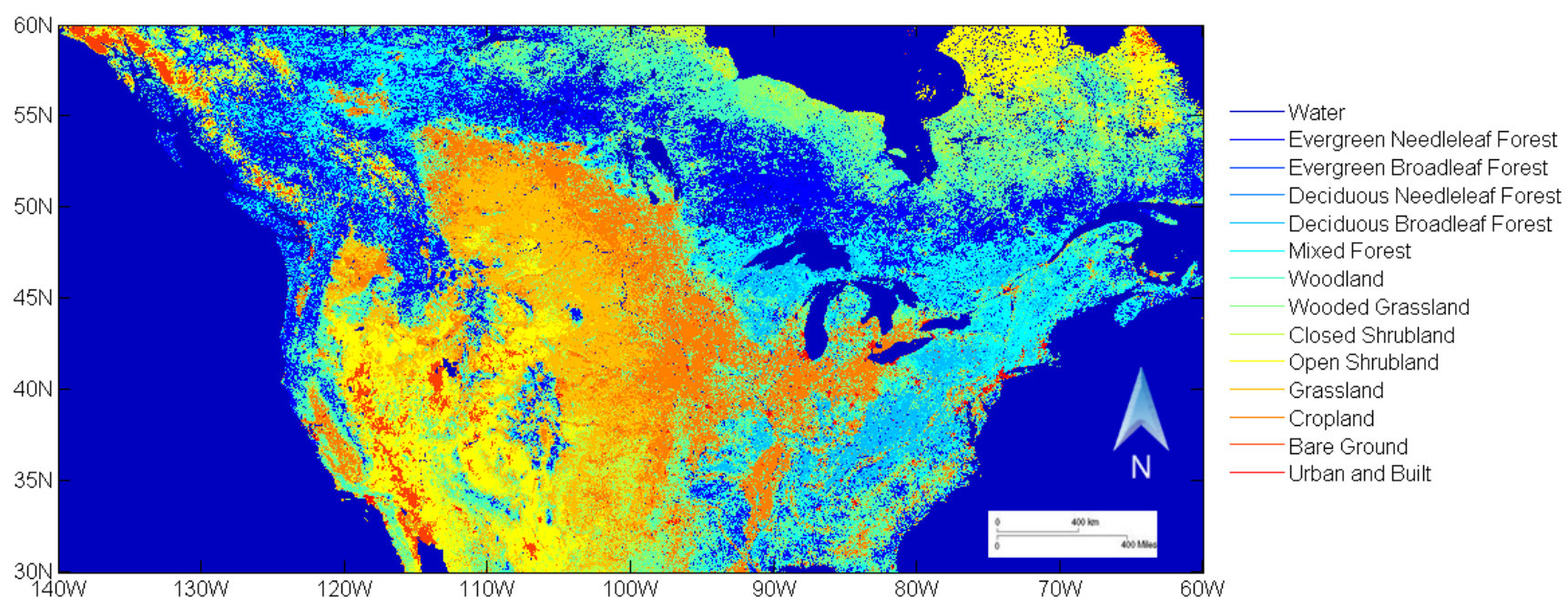

Global land classification data (Figure 4), derived from Advanced Very High Resolution Radiometer (AVHRR) with a spatial resolution of 1 kilometer, was acquired from the University of Maryland Global Land Cover Facility (www.landcover.org). The data was created in 1998 through the collection of AVHRR images between 1981 and 1994 and contains 13 classes. They are the following: evergreen needleleaf forest, evergreen broadleaf forest, deciduous needleleaf forest, deciduous broadleaf forest, mixed forest, woodland, wooded grassland, closed shrubland, open shrubland, grassland, cropland, bare ground, and urban and built-up. The NCDC stations' latitude and longitude values and the land classification latitude and longitude grids allowed for determination of the associated land classification pixel values. After the stations were classified into various land types, the rate of agreement between the IMS product and the NCDC snow depth data was determined for each land category. The calculation was described earlier. In addition to the rate of agreement (\%), the percentage of snow covered observing stations was recorded for each day by dividing the sum of the number of stations with a snow depth greater than zero by the number of stations with a snow depth recording of 0 , trace, or a discrete value multiplied by a hundred.

The snow classification data (Figure 5) contains 6 classes including: tundra, cold taiga, maritime, ephemeral, prairie, and warm taiga derived based on unique ensembles of textural, stratigraphic and 
climate characteristics used in this study $[13,14]$. After the stations were classified into various snow types, the rate of agreement between the IMS product and the NCDC snow depth data was determined for each snow category. The percentage of snow covered observing stations for each day was noted as well. A time series analysis of the rate of agreement between the IMS product and the NCDC observing stations was performed for snow depths within the following intervals: trace $-3 \mathrm{~cm}, 3-6 \mathrm{~cm}$, 6-9 $\mathrm{cm}$ and $9-12 \mathrm{~cm}$.

Figure 5. A snow cover classification image covers study area (continental USA) contains 6 classes including: tundra, cold taiga, maritime, ephemeral, prairie, and warm taiga (Source: Liston, 2012).

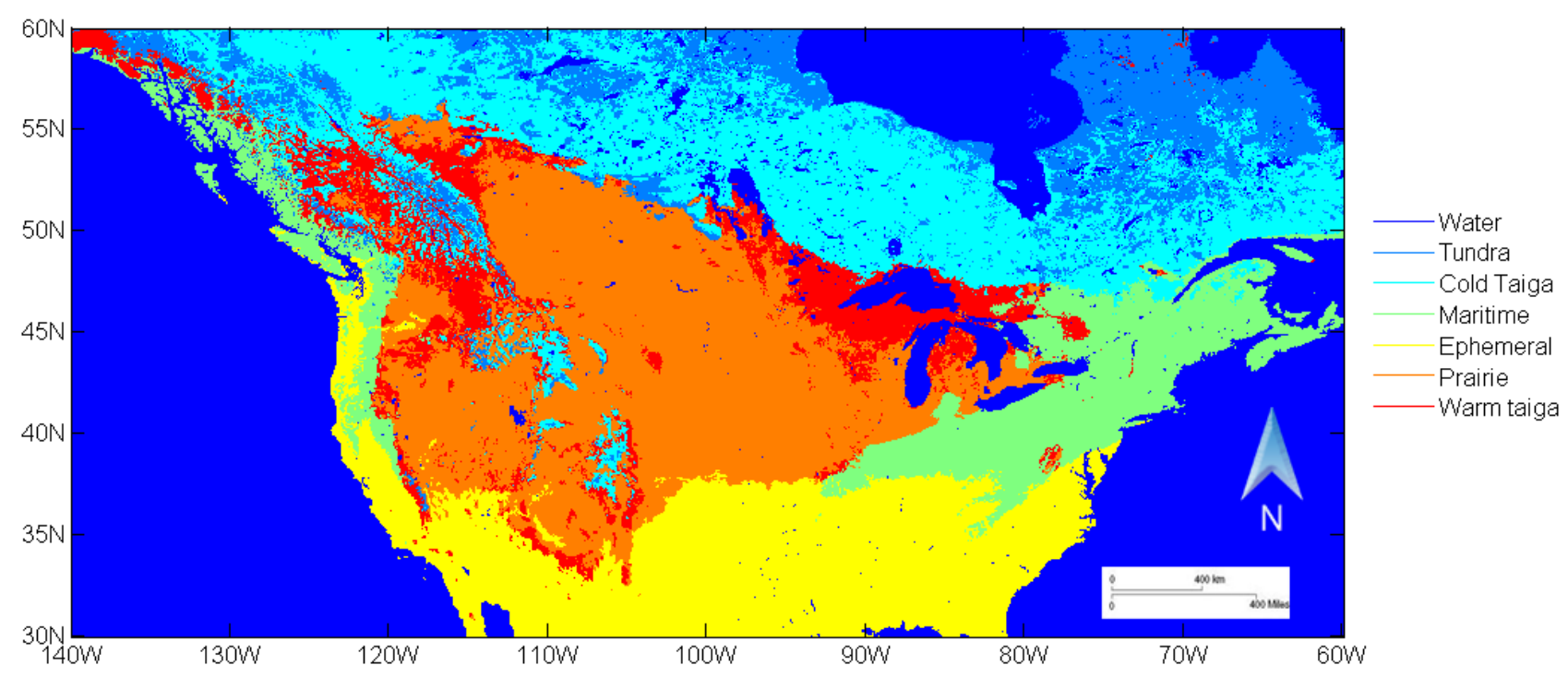

\section{Results and Discussion}

The analysis of a correlation time series between the IMS product and the NCDC stations involves a heavier focus on the winter months than the summer months. This is because the likelihood of a mismatch between an IMS pixel and NCDC station reading is higher during the winter season. The rate of agreement between the IMS product snow extent and NCDC snow depth records ranges from 79-100\% (Figure 6). The highest agreement between the IMS and NCDC station readings occur during the summer (about 100\%). Very few stations are covered with snow during the summer resulting in higher rate of agreements. General trends include the lowering of the rate of agreement during snow accumulation and ablation periods. Compared to NCDC station data, the IMS snow detection has less agreement in the early winter season. The IMS snow detection rate improves to about $80-90 \%$ later in the season (January and February) when snow cover extent increases.

\subsection{Effects of Land Cover}

The distribution of the stations among the various land classes varies greatly (Table 1). None of the observing stations are classified as evergreen broadleaf forest and deciduous needleleaf forest. Mixed pixels would be a possible reason for this occurrence. Woodland, wooded grassland, grassland, and cropland time series plots are shown in Figure 7. Selection of these land classes were based on the 
large number of NCDC stations within each class. The rate of agreement between the IMS product and the NCDC stations was higher for the woodland and wooded grassland areas, and lower for the grassland and cropland areas. There was also more consistency, or rate of agreement, in the values for both woodland and wooded grassland than grassland and cropland. The lower agreement in grassland area could be related to fragmented and shallow snow cover over the southern part of study area, which complicate snow detection over $4 \mathrm{~km}$ pixel size. The time series of the percentage of NCDC snow covered stations was fairly similar in magnitude and shape for woodland, wooded grassland, grassland and cropland. The number of snow covered stations makes up approximately $25 \%$ of all the stations in each land class in the winter.

Figure 6. Rate of agreement between IMS snow product and NCDC snow depth records over the January 2006-February 2010 study period.

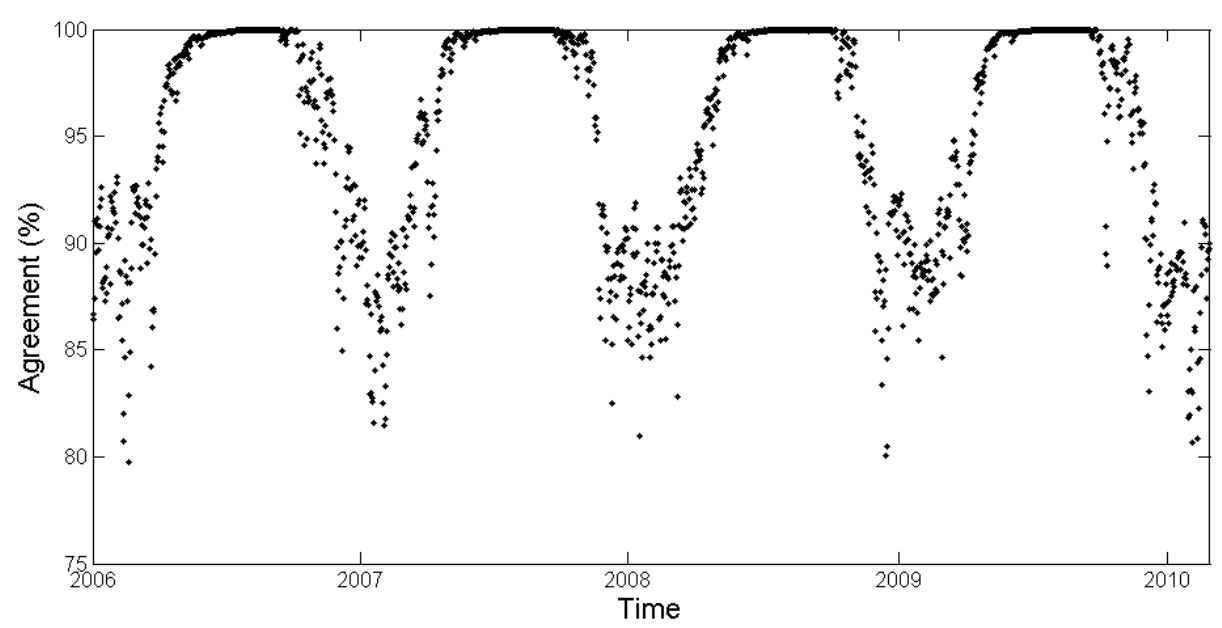

Table 1. Number of NCDC stations within each land class using land cover classification data derived from Advanced Very High Resolution Radiometer (AVHRR) for continental USA.

\begin{tabular}{cc}
\hline Land Class & NCDC Stations \\
\hline Evergreen Needleleaf Forest & 391 \\
Evergreen Broadleaf Forest & 0 \\
Deciduous Needleleaf Forest & 0 \\
Deciduous Broadleaf Forest & 523 \\
Mixed Forest & 450 \\
Woodland & 1,017 \\
Wooded Grassland & 1,370 \\
Closed Shrubland & 341 \\
Open Shrubland & 291 \\
Grassland & 1,260 \\
Cropland & 2,047 \\
Bare Ground & 33 \\
Urban and Built-up & 749 \\
\hline
\end{tabular}


Figure 7. Rate of agreement of the IMS snow map to snow reports from Cooperative network stations for selected land classes (Blue markers show rate of agreement (\%), and black markers show the percent of snow covered NCDC stations).
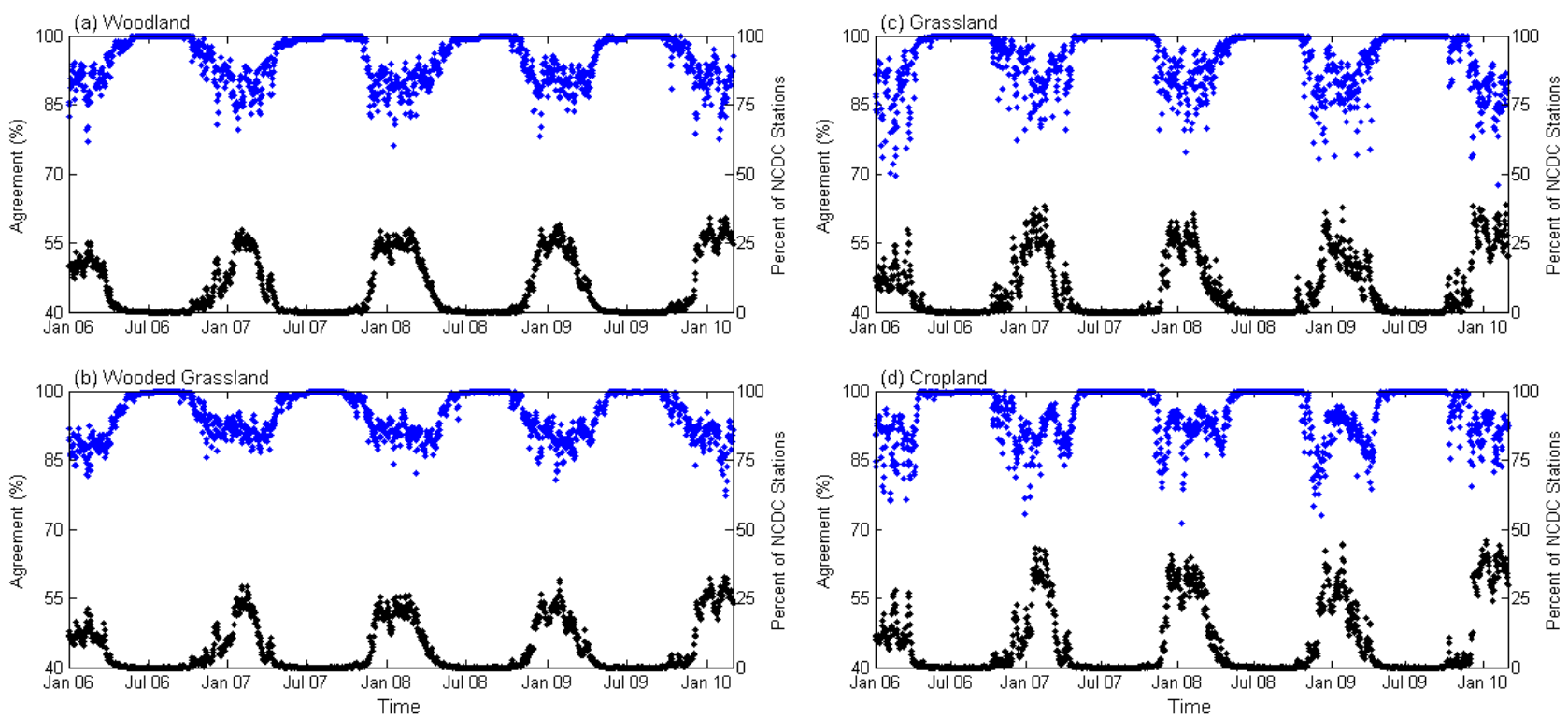

Table 2. Number of NCDC stations falling within each snow class estimated from the snow cover classification dataset for the continental USA.

\begin{tabular}{cc}
\hline Snow Class & NCDC Stations \\
\hline Tundra & 10 \\
Cold Taiga & 41 \\
Maritime & 1,341 \\
Ephemeral & 3,861 \\
Prairie & 2,795 \\
Warm Taiga & 564 \\
\hline
\end{tabular}

\subsection{Relations with Snow Type}

The number of stations in each snow class varies in magnitude. Thousands of stations are found within the maritime, ephemeral, and prairie classes, a few hundred in the warm taiga class and less than a hundred in the remaining classes of tundra, and cold taiga (Table 2). Plots for select snow classifications of maritime, ephemeral, prairie, and warm taiga are shown in Figure 8. Selection was based on the number of NCDC stations present in each snow class. Higher rate of agreement between the IMS product and NCDC stations exists in ephemeral snow areas than maritime, prairie and warm taiga areas. The rate of agreement for ephemeral snow ranges from $73 \%$ to $100 \%$, although most values appear above $85 \%$. For the maritime, prairie and warm taiga, the rate of agreement varies from $58-100 \%, 68-100$, and $62-100 \%$ respectively. The percentage of snow covered stations is around 50\% in maritime, prairie, and warm taiga. On the other hand, the ephemeral is much lower at around $15 \%$. 
Figure 8. Rate of agreement of IMS pixels and NCDC stations for selected snow classes (Blue markers are associated with rate of agreements (\%), and black markers are associated with percent of snow covered NCDC stations).
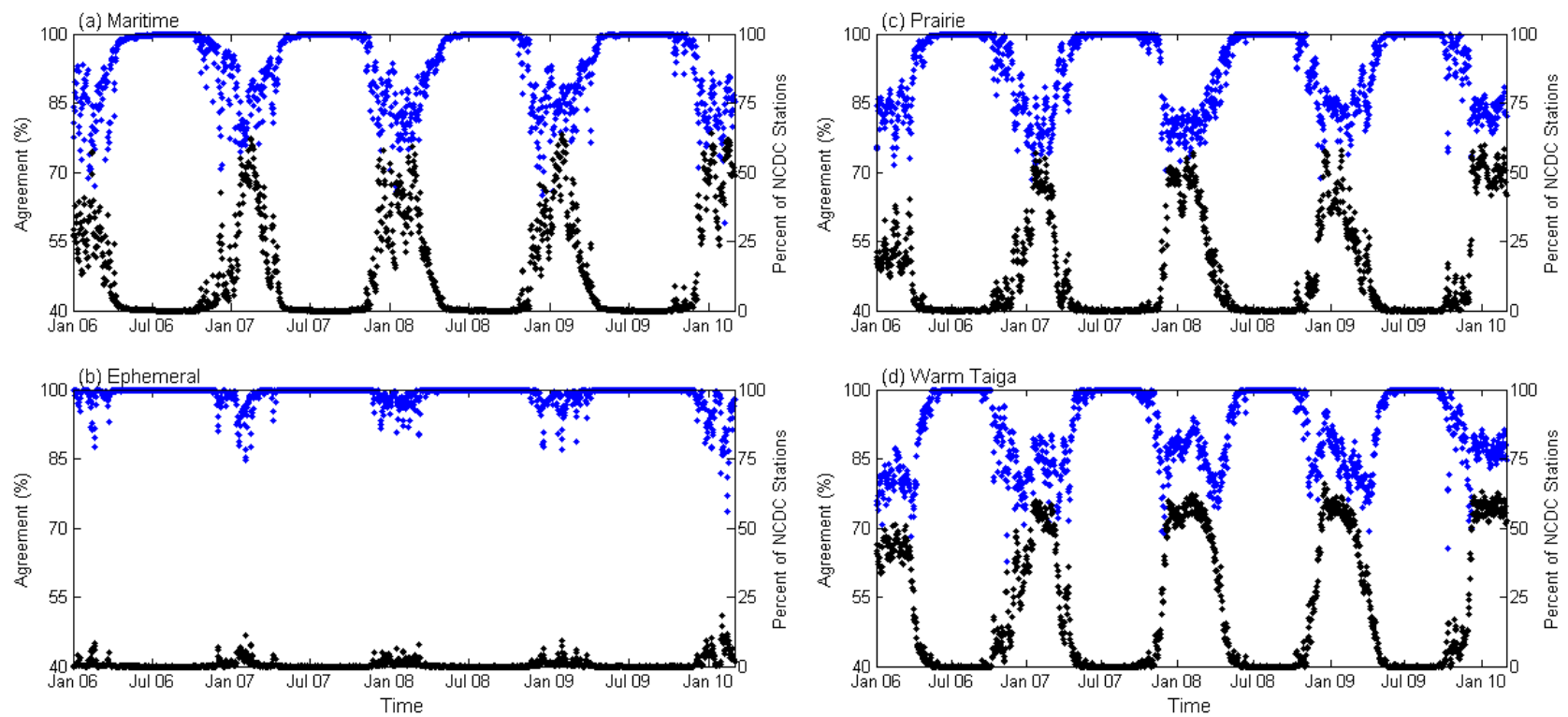

Figure 9. Agreement of the IMS product and NCDC snow covered stations for selected snow depth ranges (Unfilled circles are associated with agreement (\%), and filled circles are associated with number of NCDC stations).
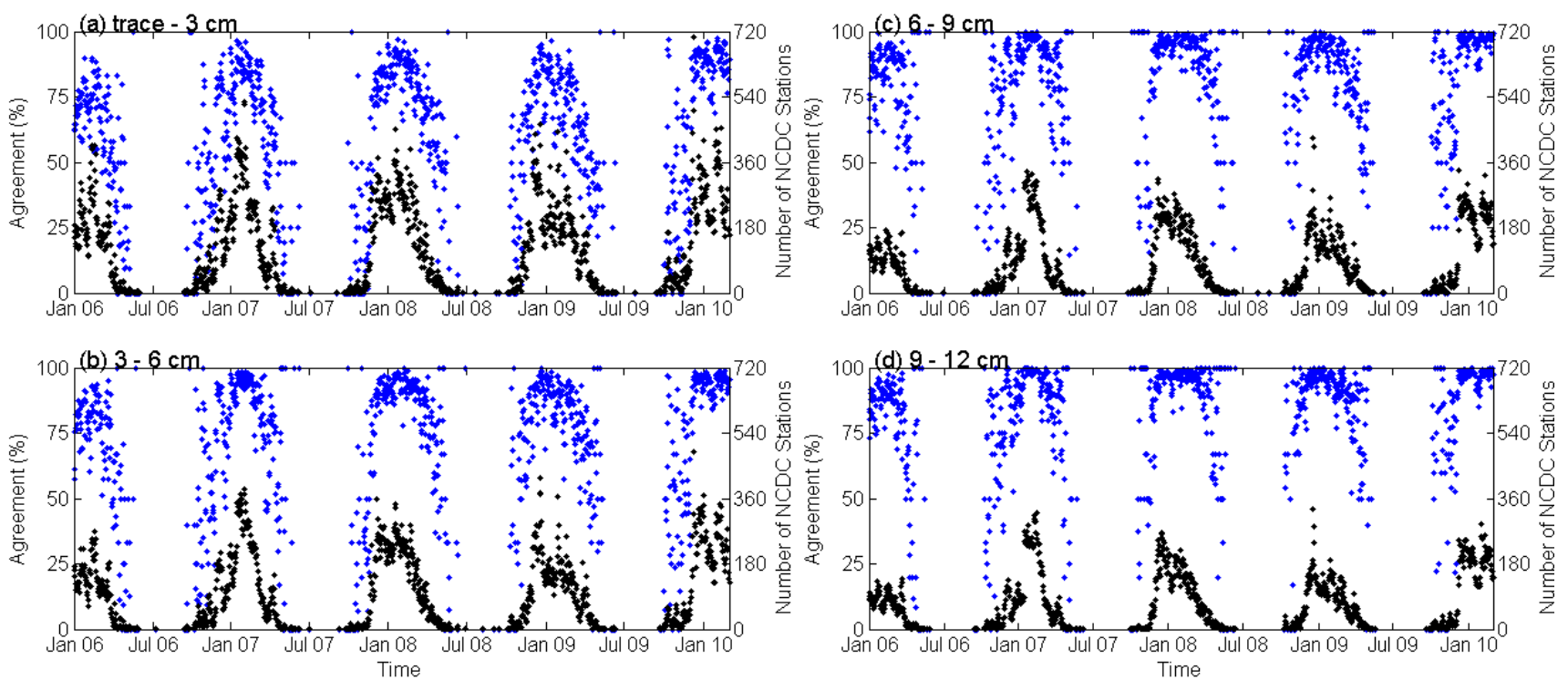

\subsection{Effects of Snow Depth}

Agreement of the IMS product and NCDC snow covered stations for selected snow depth ranges including: trace- $3 \mathrm{~cm}, 3-6 \mathrm{~cm}, 6-9 \mathrm{~cm}$, and 9-12 cm are shown in Figure 9. During the peak winter time, around $20 \%$ of NCDC stations are covered by snow. All four snow depth intervals appear to have the same cyclical shape wherein the percentage of correct agreement reaches a peak during the winter months and dips down to zero during the summer months, due to none of the stations being observed 
with snow. It may be interpreted from Figure 9 that the agreement between the snow extent of the Interactive Multi-sensor Snow and Ice Mapping system and the snow depth values of the National Climatic Data Center observing stations increases with increasing snow depth. There are more days in which the percentage of correct agreement (\%) reaches $100 \%$ for the larger snow depth intervals of 6-9 $\mathrm{cm}$ and $9-12 \mathrm{~cm}$ than the smaller snow depth intervals of trace $-3 \mathrm{~cm}$ and $3-6 \mathrm{~cm}$.

The plots in Figure 10 suggest that the agreement between the IMS and NCDC stations was quite high from November 2008-February 2009. As more snow falls onto the area, the agreement between the two switches from one of no snow-no snow (cyan) to snow-snow (blue). In terms of geographical agreements and disagreements between the NCDC stations and IMS snow product shown in Figure 10, the east coast has a higher agreement despite seasonal changes from November 2008 to February 2009. There are more red markers present in Figure 10 than green ones, which suggest the IMS tends to overestimate snow cover compared to NCDC stations, particularly over the Nebraska Oklahoma region. This overestimation could be attributed to higher albedo from tallgrass prairies confused with snow albedo.

Figure 10. Map shows agreement and disagreement between the NCDC stations and IMS snow product. (BLUE: IMS: snow, NCDC: snow; GREEN: IMS: no snow, NCDC: snow; RED: IMS: snow, NCDC: no snow; CYAN: IMS: no snow, NCDC: no snow).
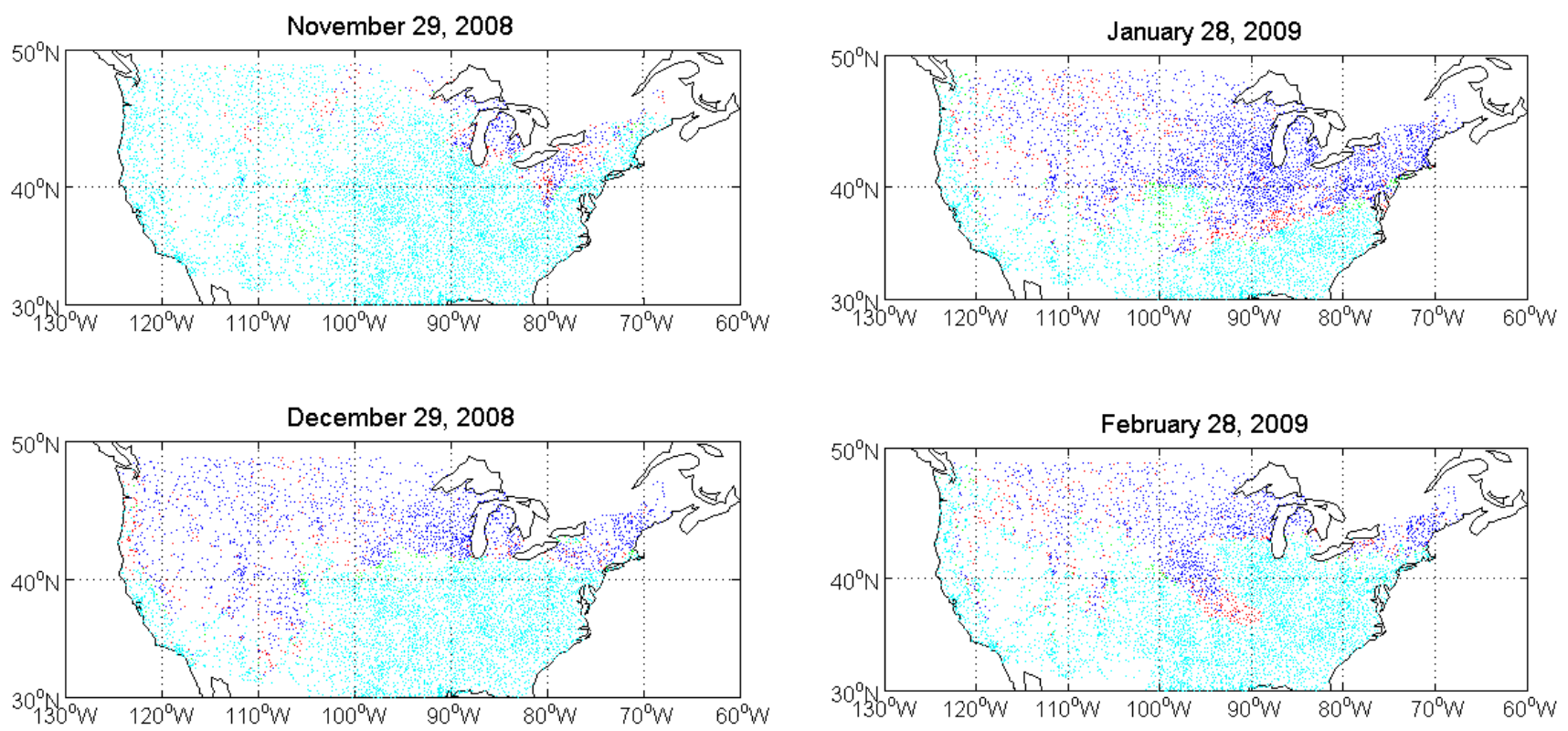

\section{Conclusions}

Detailed characterization of the quality of NOAA IMS interactive snow maps presents an important issue. This product is actively used in various environmental applications, including, in particular numerical weather prediction and climate models. Matching and comparing the IMS snow cover data with in situ observations of snow cover is a straightforward and reliable approach to estimate the accuracy of the remote sensing product. In this study the comparison of IMS maps with in situ snow observations conducted over a period of four years has demonstrated a good correspondence of the data sets. The rate of agreement between the products mostly ranges between $80 \%$ and $90 \%$ during the 
Northern Hemisphere winter season when about a quarter to one third of the territory of continental US is covered with snow. These values can be considered as an adequate estimate of the IMS snow mapping accuracy. Although the agreement rate between IMS and in situ observations increases to 95-100\% in late spring, summer and early fall seasons, this should not be attributed to better snow mapping accuracy but rather to the lack of snow cover over the study area during this time of the year.

A large part of mismatches between the IMS product and in situ data is due to inability of human analysts to accurately reproduce snow cover distribution changes during strong snow storms. In these cases the land surface in the satellite optical imagery used by analysts may be obscured by clouds for an extended period of time. The difference in the spatial resolution of the two datasets can also contribute to the disagreement. The latter factor has a larger effect in the mountainous areas where the snow cover distribution is highly inhomogeneous and in situ observations of snow often cannot be representative for the snow cover over a larger, several kilometers wide area corresponding to the IMS pixel size. Snow cover observations at NCDC stations are typically performed early in the morning. At the same time IMS maps are generated in the afternoon, Eastern Standard Time (EST) and analysts are trying to use the most recent images in the process. This time difference between observations presents another factor that causes the disagreement between IMS and in situ data. The effect of the time difference is expected to be the largest during fast changes in the snow cover distribution. This includes fast-moving snow storms and periods of active snow melt.

When mapping snow cover IMS analysts are using the same technique and similar sources of data (e.g., satellite imagery, in situ data, and automated snow remote sensing products) over the whole Northern Hemisphere. Therefore it is reasonable to assume that the accuracy of snow cover mapping over the mid-latitude region of Eurasia would be quite similar to the accuracy observed over North America.

\section{Acknowledgements}

This study was supported and monitored by National Oceanic and Atmospheric Administration (NOAA) under CREST Grant \#NA11SEC4810004. The statements contained within the manuscript/research article are not the opinions of the funding agency or the US Government, but reflect the authors' opinions. The authors are grateful to Glen Liston from CIRA, Colorado State University for providing snow classification data and useful detailed discussion regarding this project. We wish to thanks NSIDC and NOAA for providing the valuable data.

\section{References and Notes}

1. Rango, A. Spaceborne remote sensing for snow hydrology applications. Hydrol. Sci. J. 1996, 41, 477-494.

2. Robinson, D.A.; Frei, A. Seasonal variability of Northern Hemisphere snow extent using visible satellite data. Prof. Geogr. 2000, 52, 307-315.

3. Tong, J.; Velicogna, I. A comparison of AMSR-E/Aqua snow products with in situ observations and MODIS snow cover products in the Mackenzie River Basin, Canada. Remote Sens. 2010, 2, 2313-2322. 
4. Kropacek, J.; Feng, C.; Alle, M.; Kang, S.; Hochschild, V. Temporal and spatial aspects of snow distribution in the Nam Co Basin on the Tibetan Plateau from MODIS data. Remote Sens. 2010, 2 , 2700-2712.

5. Zhang, Y.; Yan, S.; Lu, Y. Snow cover monitoring using MODIS data in Liaoning Province, Northeastern China. Remote Sens. 2010, 2, 777-793.

6. Helfrich, S.R.; McNamara, D.; Ramsay, B.H.; Baldwin, T.; Kasheta, T. Enhancements to, and forthcoming developments in the Interactive Multisensor Snow and Ice Mapping System (IMS). Hydrol. Process. 2007, 21, 1576-1586.

7. Fetterer, F.; Webster, K. IMS Daily Northern Hemisphere Snow and ICe Analysis at $4 \mathrm{~km}$ and $24 \mathrm{~km}$ Resolution; Available online: http://nsidc.org/data/docs/noaa/g02156_ims_snow_ice_analysis/ index.html (accessed date 5 January 2010).

8. Ramsay, B.H. Prospects for the Interactive Multisensor Snow and Ice Mapping System (IMS). In Proceedings of 57th Eastern Snow Conference, Syracuse, NY, USA, 18-19 May 2000.

9. Rodell, M.; Houser, P.R. Updating a land surface model with MODIS-derived snow cover. $J$. Hydrometeorol. 2004, 5, 1064-1075.

10. Déry, S.J.; Brown, R.D. Recent Northern Hemisphere snow cover extent trends and implications for the snow-albedo feedback. Geophys. Res. Lett. 2007, 34, L22504.

11. Brubaker, K.L.; Pinker, R.T.; Deviatova, E. Evaluation and comparison of MODIS and IMS snow-cover estimates for the Continental United States using station data. J. Hydrometeorol. 2005, 6, 1002-1017.

12. Ge, Y.; Gong, G. Observed inconsistencies between snow extent and snow depth variability at regional/continental scales. J. Climate 2008, 21, 1066-1082.

13. Liston, G.E.; Sturm, M. A global snow-classification dataset for Earth-system applications. 2012, in preparation.

14. Sturm, M.; Holmgren, J.; Liston, G.E. A seasonal snow cover classification system for local to global applications. J. Climate 1995, 8, 1261-1283.

(C) 2012 by the authors; licensee MDPI, Basel, Switzerland. This article is an open access article distributed under the terms and conditions of the Creative Commons Attribution license (http://creativecommons.org/licenses/by/3.0/). 